\title{
ASSISTÊNCIA A SAÚDE DO RECÉM-NASCIDO COM BAIXO PESO
}

\author{
Kássia Bandeira GALVÃO ${ }^{1}$
}

Ms. Janieiry Lima de ARAÚJO²

Esp. Renata Borges de VASCONCELOS ${ }^{3}$

Ms. Gabriele Maria Dantas DINIZ4

Ellany Gurgel Cosme do NASCIMENTO 5

\begin{abstract}
${ }^{1}$ Graduanda em enfermagem pela Universidade do Estado do Rio Grande do Norte, kassya_galvao@ hotmail.com
${ }^{2}$ Enfermeira, UFRN, docente do departamento de enfermagem na Universidade do Estado do Rio Grande do Norte, UERN. Email- janieiry@ hotmail.com

${ }^{3}$ Enfermeira. Hospital e Maternida Venâncio Raimundo de Sousa, Horizonte/CE. E-mail - renatinha bv@ hotmail.com

${ }^{4}$ Enfermeira, Secretaria de Saúde do Estado do Rio Grande do Norte. E-mail - gabrieledinizz@ hotmail.com

${ }^{5}$ Enfermeira, docente do departamento de enfermagem na Universidade do Estado do Rio Grande do Norte, UERN. Email- ellanygurgel@hotmail.com. Endereço: Universidade do Estado do Rio Grande do Norte-UERN, Campus Avançado Prof ${ }^{a} \mathrm{M}^{\mathrm{a}}$. Elisa de Albuquerque Maia-CAMEAM, Pau dos Ferros, RN, no endereço BR 405, KM 153, Arizona 59900-000 - Pau dos Ferros - RN. Telefone: (84) 9648-5999 (Autor para correspondência).
\end{abstract}

\section{Recebido em: 01/04/2015 - Aprovado em: 20/08/2015 - Disponibilizado em: 30/10/2015}

\begin{abstract}
RESUMO
Trata-se de um estudo transversal, quanti-qualitativo, com base em pesquisa documental e entrevista com profissionais de saúde que objetivou analisar a assistência neonatal prestada nas maternidades de Pau dos Ferros/RN aos recémnascidos com baixo peso ao nascer. Com base em pesquisa documental junto as declarações de nascidos vivos(DNV) do ano de 2012 e entrevista com profissionais de saúde e gerentes atuantes na Maternidade Santa Luiza de Marilac (MSLM) e Hospital Dr. Cleodon Carlos de Andrade (HCCA), ambos situados em Pau dos Ferros/RN. Os participantes da pesquisa, no total de 35 sujeitos, divididos em três grupos. Os dados coletados através das entrevistas foram analisados e interpretados a partir do método da Análise Temática o que gerou quatro temas de discussão. Em relação à pesquisa documental, os dados serão apresentados em gráficos e analisados descritivamente. Como resultados da análise temática tem-se que: o cuidado de saúde ao RNBPN realizado pelos profissionais apresenta deficiências. Pois, o cuidado não difere do cuidado prestado a outros RN. O suporte dado em situação de intercorrência com o RNBPN segue as regras da referência e contra referência, ou seja, é providenciada a transferência para unidades mais complexas de atendimento neonatal, especialmente, Mossoró e Natal. O conhecimento sobre as políticas de saúde voltadas para o RN, em especial para o RNBPN é deficiente, por vezes, apenas no campo teórico. O estudo demonstrou a deficiência de conhecimento dos profissionais em relação à assistência ao RNBPN, sendo necessárias medidas de educação permanente em saúde, ações preventivas sobre os fatores de risco relacionado ao BPN e a instalação de UTI Neonatal e banco de leite, para garantir suporte adequado àqueles que por ventura venha a apresentar baixo peso ao nascer, de forma que possam ser assistidos com qualidade mediante suas necessidades de saúde e problemas apresentados.
\end{abstract}

PAlaVRAS ChAVE: Assistência à Saúde; Recém-Nascido de Baixo Peso; Assistência ao Parto. 


\section{INTRODUÇÃO}

Em relação à assistência maternoinfantil as ações de saúde desenvolvidas proporcionaram a diminuição das taxas de mortalidade desses grupos populacionais (KRAMER, 1987). Entretanto, os óbitos de neonatos se mantiveram em coeficientes estáveis, percentualmente, porém em algumas regiões do país há uma tendência a aumento. Os fatores condicionantes do risco neonatal que ainda subsistem se encontram relacionadas ao baixo peso ao nascer $(<2500$ g) e o peso insuficiente ao nascer (2500 a 3000 g) (CARNIEL et al, 2008) Além desses fatores, outros determinam o risco neonatal, como as condições e estilos de vida da mulher, acesso aos serviços de pré-natal e parto, fatores biológicos adaptativos relacionados à gestação e ao nascimento (KENNER, 2001).

Observa-se que de acordo com Carniel et al (2008) as taxas de baixo peso ao nascer (BPN) são variáveis nas diversas regiões do mundo, com evidentes desvantagens para os países menos desenvolvidos, pois estão associadas a condições socioeconômicas desfavoráveis e podem ser consideradas como um indicador de nível de saúde da população. Assim, em países desenvolvidos da Europa, como Itália, França, Portugal, Suíça, Suécia, Noruega, Irlanda e Espanha, a porcentagem de BPN varia entre 4 a 5. Nos Estados Unidos esta taxa é de $7,6 \%$, porém com variação de
$13,1 \%$ na população negra e $4,8 \%$ na branca. As maiores proporções são as da Índia (33\%) e as de Bangladesh (50\%). Na América Latina e Caribe, o valor médio é de 9\%. No Brasil, em 2001, a média de BPN foi de 7,9\%, sendo a maior porcentagem no Estado do Rio de Janeiro $(9,4)$ e a menor em Roraima $(5 \%)$. Em geral, nos países desenvolvidos estas taxas são principalmente decorrentes de partos prematuros, observados em dois terços dos nascimentos de crianças com BPN. Para os países em desenvolvimento, esta ocorrência se deve, na maioria das vezes, ao retardo de crescimento intrauterino.

A detecção do peso dos recémnascidos (RN) é um fator isolado, que afeta a morbidade e mortalidade neonatal, como também, pode atuar sobre esses indicadores na fase infantil. De modo que, crianças com baixo peso ao nascer, ou seja, <2.500 g, apresentam uma maior mortalidade nas primeiras semanas de vida. $\mathrm{O}$ baixo peso ao nascer pode ser devido à prematuridade, ao retardo de crescimento intrauterino ou a uma combinação de ambos, os quais apresentam etiologias e consequências diferentes. (ZAMBONATO et al, 2004).

Desta forma, Paula et al (2010) aponta que a importância do conhecimento acerca das condições de saúde e avaliação desses RN contribui de forma importante para $o$ entendimento das taxas de mortalidade e morbidade infantis, principalmente, a 
mortalidade neonatal. Sendo esta determinada por diversos fatores correlacionados, dentre eles: condições sociais, econômicas e ambientais às quais a mulher se encontra durante o período de gestação.

Diante do exposto, o objetivo desta pesquisa foi analisar a assistência neonatal prestada na Maternidade e Hospital de Pau dos Ferros/RN aos recém-nascidos com baixo peso.

\section{METODO}

Trata-se de um estudo transversal, quanti-qualitativo, com base em pesquisa documental e entrevista com profissionais de saúde. A pesquisa foi realizada no Hospital Dr. Cleodon Carlos de Andrade (HCCA), na Maternidade Santa Luiza de Marilac (MSLM) e a pesquisa documental na Secretaria de Saúde e Saneamento de Pau dos Ferros (SMS Pau dos Ferros). Estes estabelecimentos de saúde estão localizados em Pau dos Ferros/RN, município situado na Mesorregião Potiguar.

Segundo dados do Instituto Brasileiro Geográfico e Estatístico - IBGE (2010) a população é de 27.745 habitantes, que ocupam uma área territorial de 259,958 $\mathrm{Km}^{2}$, com Densidade demográfica de 106,73 hab/ $\mathrm{Km}^{2}$. Caracteriza-se como uma cidade de pequeno porte, de caráter urbano, tem sua pirâmide etária composta por uma população expressiva de jovens e adultos (entre 20 e 50 anos). Segundo dados do Sistema Nacional de Nascidos Vivos (SINASC) que apontam que em 2010, em Pau dos Ferros/RN, observou-se o nascimento de 484 nascidos vivos. O número de óbitos de crianças menores de um ano no município, de 1995 a 2010, foi 187.

Os participantes da pesquisa que se submeteram à entrevista semiestruturada foram recrutados entre os profissionais de saúde atuantes na Maternidade Santa Luiza de Marilac (MSLM) e do Hospital Dr. Cleodon Carlos de Andrade (HCCA). Para facilitar o agrupamento das informações da coleta dos dados, estes foram divididos em três grupos: Grupo 01 - Profissionais de Nível Superior; Grupo 02 - Profissionais de Nível Médio e Grupo 03 - Profissionais Gerentes de Saúde.

Quadro 01: Quantitativos dos profissionais segundo estabelecimento de saúde e sua categoria:

\begin{tabular}{|c|c|c|c|c|}
\hline Estabelecimento & \multicolumn{1}{|c|}{ Grupo } & \multicolumn{1}{c|}{ Grupo } & \multicolumn{1}{c|}{ Grupo } & Total \\
& $\mathbf{1}$ & $\mathbf{2}$ & $\mathbf{3}$ & \\
\hline HCCA & 16 & 14 & 2 & $\mathbf{3 2}$ \\
\hline MSLM & 4 & 17 & 1 & $\mathbf{2 2}$ \\
\hline TOTAL & $\mathbf{2 0}$ & $\mathbf{3 1}$ & $\mathbf{3}$ & $\mathbf{5 4}$ \\
\hline
\end{tabular}

Os critérios de inclusão foram: a) Profissionais que trabalham no serviço no período mínimo de cinco anos. b) Profissionais que estão intimamente ligados à assistência ao recém-nascido. e) Ser gestor do estabelecimento hospitalar - maternidade. Os critérios de exclusão foram: a) Profissionais que estiverem no período de férias, afastamento, ou licença. 
Participaram da pesquisa 35 profissionais, sendo: $12(34,3 \%)$ participantes enquadrados no Grupo I, 21 (60\%) no Grupo II e $02(5,7 \%)$ no Grupo III.

Em relação à pesquisa documental, que ocorreu na Secretaria de Saúde e Saneamento (SMSS de Pau dos Ferros) adotamos como base amostral o ano de 2012, com um total de $1589 \mathrm{DNV}$, aptas segundo os critérios inclusivos e exclusivos. O critério de inclusão consistiu em: a) Incluir as DNV preenchidas no ano, de 2012. E o critério de exclusão consistiu em: a) Excluir as DNVs que não foram preenchidas na cidade de $\mathrm{Pau}$ dos Ferros/RN. O período de coleta dos dados ocorreu entre 30 de Setembro de 2013 e 01 de Novembro de 2013.

Quadro 02: Quantitativo de DNVs registradas em Pau dos Ferros/RN no ano de 2012.

\begin{tabular}{|lc|}
\hline Local do Nascimento & Ano 2012 \\
\hline HCCA & $883(55,5 \%)$ \\
\hline MSLM & $706(44,5 \%)$ \\
\hline TOTAL & 1589 \\
\hline
\end{tabular}

Os dados coletados através das entrevistas foram analisados e interpretados a partir do método da Análise Temática e a pesquisa através do roteiro norteador nas DNV foi analisada estatisticamente.

Este projeto de pesquisa foi aprovado no Comitê de Ética em Pesquisa da Universidade do Estado do Rio Grande do
Norte (CEP/UERN), emitido em 02 de julho de 2013, sob o CAAE (Certificado de Apresentação para Apreciação Ética) $\mathrm{n}^{\circ}$ 18626713.7.0000.5294.

\section{RESULTADOS}

As Declarações de Nascidos Vivos é um documento preenchido em todo território nacional, para todos os nascidos vivos, sejam quais forem às circunstâncias de ocorrência do parto (hospital, maternidade, serviços de urgência/emergência, domicílios, vias públicas, etc.). Pode ser preenchida por médico, por membro da equipe de enfermagem da sala de parto, do berçário, da unidade de internação ou por outra pessoa previamente treinada para tal fim.

Das 1589 DNV preenchidas pela MSLM e HCCA, 90 apresentaram RN com Baixo Peso ao Nascer (Gráfico 1).

Gráfico 1: Quantitativo de DNV com BPN segundo Mês de Nascimento. Pau dos Ferros/RN, 2013.

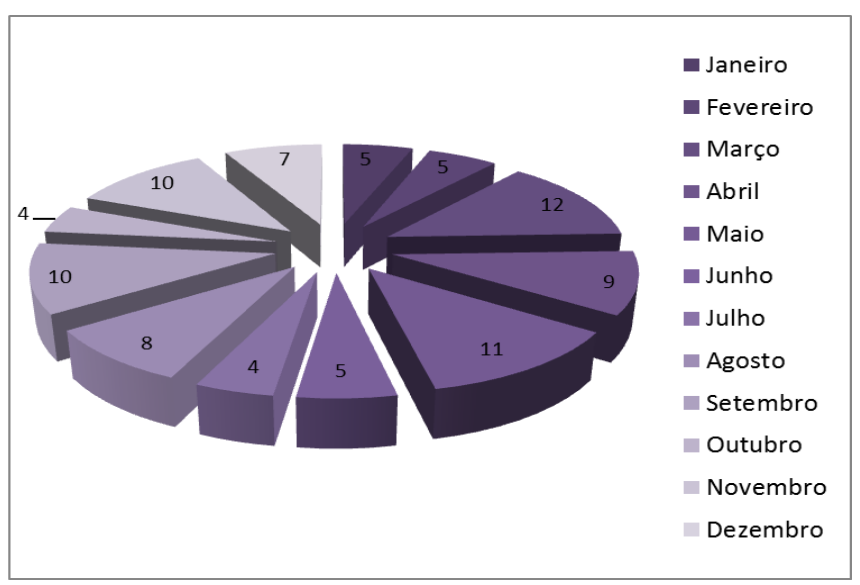


Quanto ao peso ao nascer 21 eram entre 300 à $1400 \mathrm{~g}$ e 69 entre 1500 à $2500 \mathrm{~g}, 51$ eram do sexo feminino, com relação ao tipo de gestação 72 eram únicas, 52 foram cesáreos, 59 vive com companheiro, 76 tem oito anos ou mais de estudo, 80 não trabalha fora do lar.

Gráfico 2: Caracterização da idade materna e da idade gestacional de RNBPN. Pau dos Ferros/RN, 2013.

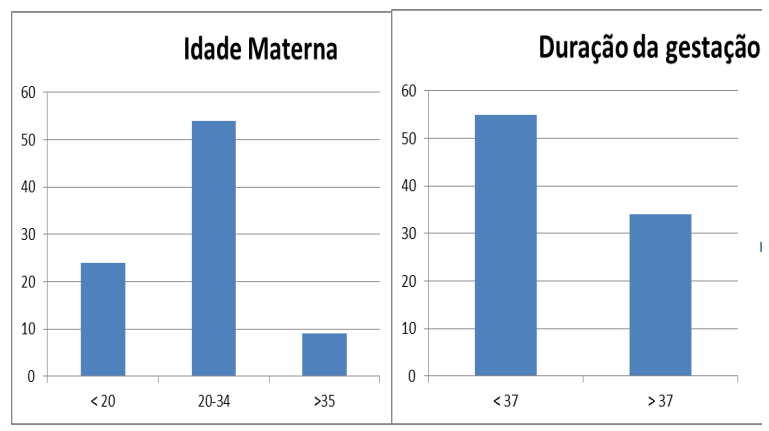

Com relação ao número de filhos anteriores ao parto do RNBPN, 43 eram nuliparas.

Gráfico 3: Caracterização da Paridade materna e filhos mortos anteriormente ao Nascimento de RNBPN. Pau dos Ferros/RN, 2013.

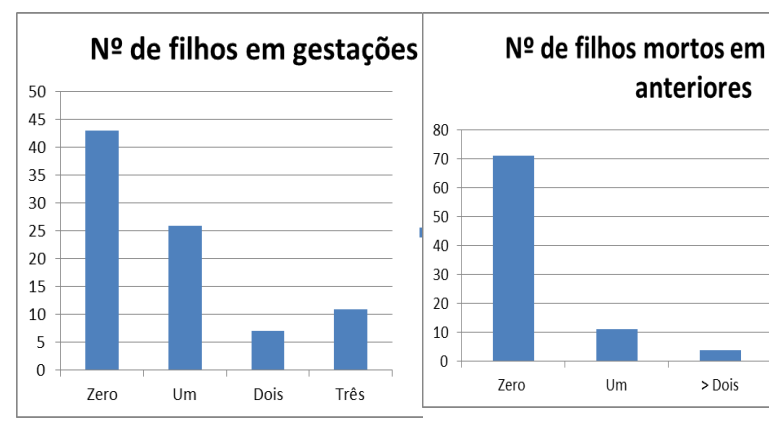

Ao analisarmos as 90 DNS de RN com BPN, encontramos em relação à variável "Identificação do RN e Endereço da Mãe" que 5 residem em Pau dos Ferros, 83 em outras cidades da região e 02 em outro estado, visto que as unidades hospitalares estudadas atendem a região do Alto Oeste Potiguar e o Estado do Ceará, devido às proximidades de fronteiras (Gráfico 3).

Sobre o número de consultas de prénatal nas DNVs de RN com BPN no ano de 2012 em instituições hospitalares de Pau dos Ferros/RN, observou-se some 36 realizaram sete consultas ou mais. ( gráfico 4)

Gráfico 4: Caracterização do Número de Consultas Realizadas no Pré-Natal de RNBPN. Pau dos Ferros/RN, 2013.

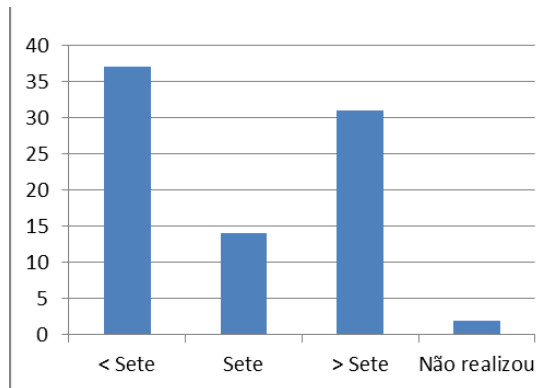

Quanto as entrevistas a amostra é predominantemente feminina, distribuídos na faixa etária entre 26 a 52 anos de idade, com formação em enfermagem. A categoria médica é constituída por cirurgiões e obstetras. E os profissionais de nível médio, são compostos por pessoal de enfermagem, sendo que algumas destes se identificaram como "parteiras". (Gráfico 5) 
Ao analisar a titulação dos

Gráfico 5: Caracterização dos participantes segundo a "Categoria Profissional". Pau dos Ferros/RN, 2013.

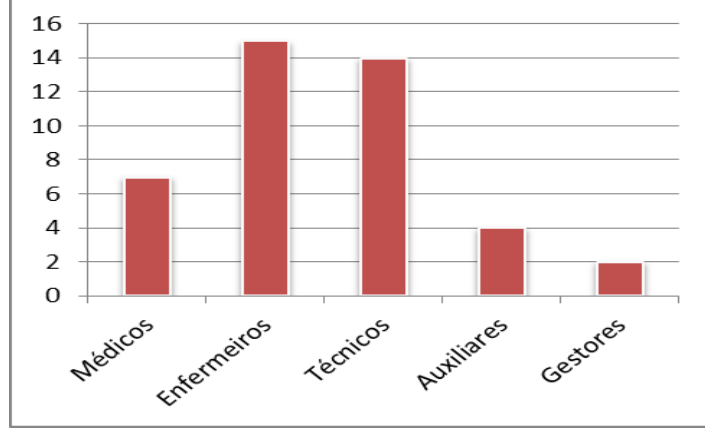

O tempo de exercício profissional 19 (51\%) tem mais de onze anos de atuação com a atenção à saúde do RN ( Gráfico 2)

Gráfico 6: Caracterização dos participantes segundo o "Tempo de Exercício da Profissão”. Pau dos Ferros/RN, 2013.

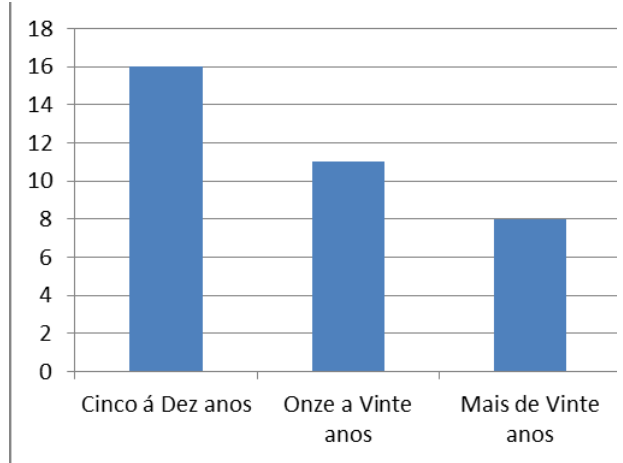

Apenas 18 entrevistados relataram ter participado de cursos na área de assistência com RN, sendo indicados: neonatologia, primeiros socorros pediátricos, cursos sobre gravidez, parto e puerpério com vistas à atenção à mãe e ao RN. profissionais é nítido que muitos se firmam na quantidade de anos que tem de serviço, atribuindo a este o fator determinante que lhe oferece condições para atuar em situações de risco com $\mathrm{RN}$, isto é, sua experiência; de maneira que a maioria não apresenta titulação na área de atenção ao RN. Salienta-se que algumas qualificações como Enfermagem em Centro Cirúrgico, Obstetrícia configuram-se como importantes, mas estas são vinculadas mais às gestantes. Frente a essa realidade, cabe refletir que se são esses profissionais que realizam ações voltadas ao $\mathrm{RN}$ e que em a maioria não apresentam titulações na área, como então está sendo realizado esse cuidado? Que atenção é dedicada exclusivamente a um caso grave, que não seja direcionado apenas ao pediatra?

\section{TEMA 01: $O$ cuidado de saúde ao $R \mathbf{N}$ com BPN realizado pelos profissionais apresenta deficiências.}

Após o parto, quando se apropriam do $\mathrm{RN}$ para fazer os primeiros cuidados e realizar as avaliações para detectar deficiências ou anomalias, o mesmo é pesado, e ao detectar o baixo peso, indaga-se que assistência específica a essa situação deve ser prestada, e como se configura $\mathrm{o}$ atendimento $\mathrm{e}$ acolhimento a esse RN. Nesse ponto, os profissionais entrevistados foram bem objetivos em suas respostas, sempre 
enfatizando os entraves que os mesmos detectam cotidianamente e as dificuldades do processo de trabalho voltado para a atenção ao RN.

[...] a gente presta toda a assistência necessária, ai se ele nasce com o baixo peso, a gente vê como ele vai reagindo horas depois, observa, coloca a mãe pra amamentá-lo e se ele não conseguir aí a gente improvisa na seringa, não tem banco de leite, contamos com a ajuda da mãe e ficamos a postos caso algo grave aconteça (AUXILIAR DE ENFERMAGEM 1).

É o seguinte, eu vou ser sincera, na realidade o cuidado é sempre o mesmo, seja ele baixo peso ou não, o nosso papel na assistência é levá-lo para o aquecedor, aspirar se tiver secreção, dá à vitamina, pesar, olhar as medidas e deixá-lo limpinho, assim eu encerro meu trabalho. É isso (TÉCNICO DE ENFERMAGEM 1).

Eu sou parteira! Aqui eu tenho bastante experiência na minha área, eu não vivo estudando mais as coisas pra me atualizar, mas eu aprendi muito e uso tudo o que eu posso aqui, o serviço não ajuda muito, tem que melhorar a estrutura, tem que ter mais material disponível, eu não tenho pena de usar, mas sempre é bom economizar, que às vezes falta, aqui só resta fazer o cuidado que sempre faço, e se eu não souber fazer, eu não deixo a criança morrer não, não tem nem perigo. Vou atrás do obstetra e peço ajuda e o que cabe a eu fazer, eu mesma vou e faço (TÉCNICO DE ENFERMAGEM 3).

O nosso papel enquanto profissional de enfermagem é acompanhar desde a chegada da gestante, o momento do parto e pós-parto, o serviço ainda é escasso em instrumental, contamos com o apoio das técnicas pra realizar os primeiros cuidados e observamos o RN, fazemos aquele acompanhamento esse é o suporte, às vezes o conhecimento sem o aparato tecnológico se torna nada, pois ficamos de mãos atadas (ENFERMEIRO 1).

Há você agora tocou em um assunto pouco discutido, eu acho que não só aqui, tenho vínculo em outra cidade e uma coisa que sempre deveria pensar e priorizar que é a atenção ao RN, à mãe que às vezes fica exposta ao risco, muitos estudos inovadores querendo discutir a Rede Cegonha, quer que eu te diga a realidade? Nós não estamos preparados para lidar com RN, a assistência é sempre a mesma, e nada cobramos e tudo fica igual, não temos o que fazer, não sei nem se estamos preparados para lidar com essas situações (ENFERMEIRO 3).

Bom, a assistência prestada aqui é deixando a mãe e o seu filho aqui em observação algumas horas depois do parto, assim podemos observar se a criança ou a mãe apresentaram alguma coisa, quando o filho nasce com baixo peso, nós ficamos atentos, incentivamos a mãe ao aleitamento assim que se encerram os primeiros cuidados, e explicamos a mãe que ela precisa ficar atenta, que o filho dela precisa adquirir peso, que ela deve realizar o acompanhamento na unidade de saúde do bairro dela, e prestamos suporte enquanto mãe e filho estiverem presentes aqui (MÉDICO 1).

Há eu também queria muito saber novos métodos para proceder aqui nessa situação à gente conta mais com as meninas lá, as técnicas, elas dão conta disso, agora se junto ao baixo peso apresentar algo mais então eu vou e assumo o controle da situação, faço o que posso, e o que dediquei anos para aprender (MÉDICO 3).

\section{TEMA 2: $O$ cuidado ao RN com Baixo}

\section{Peso ao Nascer não difere do cuidado a outros RN.}

Quais as medidas tomadas pelos serviços de saúde quando o RN já foi pesado e é classificado como baixo peso. Observouse que a assistência prestada é realizada de forma igualitária, seja para o RN com baixo peso ou não e, mediante a gravidade é acionado outros profissionais para dá suporte, mas aqui foram esclarecidas que essas medidas podem ser ou na instituição ou direcionadas a outro local. 
As medidas tomadas é providenciar para que o RN possa tomar o leite, é providenciar os testes, e se nenhum médico puder fazer nada, a gente procura um pediatra (AUXILIAR DE ENFERMAGEM 2).

Bem a gente aqui faz os passos iniciais né? As medidas tomadas é providenciar para que ele fique aquecido, a alimentação, os exames. Observamos a respiração, se fica com as mãos e pés roxinhos, e se apresenta alguma deficiência. E se apresentar, pede a avaliação do médico (TÉCNICO DE ENFERMAGEM 4).

Eu já percebo logo, quando pego a criança na sala de cirurgia, eu já sinto se ela é muito pequenininha, se o Apgar dela tá bom, às vezes nasce com baixo peso, mas segue bem, então há casos e casos, mas o enfermeiro e o médico sempre ficam a postos. E se a criança tiver dificuldade de respirar por causa da secreção eu mesma aspiro e assim já vejo se era esse o real problema. A coisa aqui é séria [...] (TÉCNICO DE ENFERMAGEM 5).

Eu tenho muita experiência aqui nesse setor, já vi muita coisa feia, muita criança parindo outra, e não é fácil lidar com a saúde, com o cuidado a criança e a mãe, que ela também precisa se recuperar, a gente leva a criança pros braços da mãe quando ela está com condições e quando não, a gente pede ao médico pra avaliar, e tem que ser atento [...], às vezes a criança morre e a gente não consegue fazer mais nada, então a gente sempre fica assim por perto (TÉCNICO DE ENFERMAGEM 6).

As medidas tomadas aqui devem ser cautelosas, porém rápidas, temos alguns contatos, temos médicos muito bons, mas às vezes não estão na escala, às vezes estamos apenas com... Como aqui é privado também temos alguns amigos profissionais que não estão na escala, mas compõem a equipe, então eles são capacitados para lidar com situações graves de RN com baixo peso, tiramos dúvidas, pensamos em métodos viáveis, aqui é assim, temos que pensar no que pode ser feito e não ficar esperando o vento soprar pra nosso lado (ENFERMEIRO 4).

O nosso papel a desempenhar é garantir todo o suporte desde a chegada e que os mesmos possam sair daqui bem, o nosso papel é realizar todo o protocolo rotineiro que temos aqui e de acordo com as respostas apresentadas pelo $\mathrm{RN}$, então pensamos em medidas cabíveis, caso contrário é encaminhar (ENFERMEIRO 5).

Nós dispomos de suporte básico para o atendimento ao RN, não temos muito suporte de equipamento, mas ainda assim conseguimos realizar ações que viabilizam um bom condicionamento ao RN, já que trabalhamos em um ambiente que atua diretamente com funções voltadas a mãe e ao $\mathrm{RN}$, ao momento que antecede e o pósparto. Temos que ser conscientes que imprevistos podem acontecer e que somos profissionais que nos qualificamos para atuar nessa área, então vamos acordar e desenvolver nosso papel, não acha? (ENFERMEIRO 6).

Depende assim, na realidade após os cuidados iniciais, depois nós sempre passamos pra saber com a mãe ou as técnicas vem nos comunicar se algo está fora do comum, você deve saber a dificuldade de lidar com patologias, ou detectar anomalias em recém-nascidos, precisamos acompanhálos, ouvir queixas da mãe que sempre enxerga algo estranho no seu filho, assim o meu papel após o parto, após a realização da cirurgia é este que eu te disse, e as medidas, em sua maioria são resolvidas aqui. (risos) (MÉDICO 4).

Na dúvida, pra não expor eu avalio as condições do RN e o encaminho, sempre olhando a questão do risco/benefício, o posicionamento da mãe, aqui eu não costumo agir por impulso, mas se não há UTI neonatal, vou buscar reforços (MÉDICO 5).

As medidas tomadas ocorrem depois de avaliarmos as condições do RN, existem problemas que podem ser detectados ao nascimento que tem como precursor o baixo peso, então a investigação torna-se fundamental, eu costumo acreditar na equipe que temos, já resolvemos muitos pepinos (...), aliás, muitas coisas que tinha tudo pra dá errado e deu certo porque resolvemos tentar, não custa tentar não é isso (MÉDICO 6). 
TEMA 3: O Suporte dado em Situação de

Intercorrência segue as regras da

Referência e Contra-Referência para

Unidades Mais Complexas.

Trata um ponto muito utilizado pelos serviços de saúde e que é o encaminhamento para outra unidades de saúde, a transferência de pacientes. Nestas situações contam-se com apoio de instituições de maior porte $\mathrm{e}$ complexidade, que se apresentam como meio de ajudar a população, não superlotar os serviços e viabilizar boas e especializadas condições de cuidado, garantindo acompanhamento necessário e o restabelecimento das boas condições de saúde. No caso das instituições hospitalares estudadas, os serviços não dispõem de UTI neonatal, nem banco de leite, tecnologias que se fazem fundamentais para possíveis necessidades apresentadas pelos RN com Baixo Peso ao Nascer.

Quando acontece a intercorrência nós organizamos a criança, a mãe, comunicamos aos familiares e aguardamos o que o médico vai decidir (AUXILIAR DE ENFERMAGEM 3).

Aqui nós oferecemos todo o suporte, deixamos a criança em boas condições, assim faz um tempo que não passamos por algo muito grave, geralmente resolvemos aqui, mas intercorrência é intercorrência, entregamos a documentação ao enfermeiro e ele ajeita os contatos lá com o médico (TÉCNICO DE ENFERMAGEM 7).

[...] quando ocorre uma intercorrência geralmente eles ligam pra Mossoró, por certo organizam essas questões de manter o RN seguro, falam com o médico de lá e explica a situação, ou então pergunta o que mais pode ser feito, às vezes a gente pensa que fez tudo e não fez (TÉCNICO DE ENFERMAGEM 8).

Aqui a parte principal a gente já faz, se não dá jeito, só ligando pra Mossoró ou Natal, os enfermeiros geralmente tomam conta da situação (TÉCNICO DE ENFERMAGEM 9).

$\mathrm{O}$ processo de encaminhar requer muito cuidado, nós temos contatos com Mossoró, com Natal, nós temos profissionais pediatras a nossa disposição, o primeiro passo, eu sempre digo é realizar nossas práticas aqui, nós conseguimos em situações angustiantes, [...] embora sem muitos aparatos, mas muitos não precisarão sair daqui e muitos nem vão precisar (ENFERMEIRO 7).

Eu particularmente não insisto muito, apresentaram sinais de dificuldade respiratória, dificuldade de mamar, hipotermia e até infecções, já encaminho (ENFERMEIRO 8).

$\mathrm{Na}$ realidade eu não coloco muita fé nessa questão de um RN sair daqui pra ir pra um lugar mais longe, às vezes parece viável, mas é arriscado, prefiro tentar todos os procedimentos cabíveis aqui, temos médicos bons também (ENFERMEIRO 9).

Nós ligamos para nossos contatos e olhamos algumas possibilidades, não enviamos RN assim, de qualquer forma, apenas se apresentarem graves de maneira que não há o que fazer (MÉDICO 7).

Às vezes sai melhor não arriscarmos encaminhá-lo, às vezes o $\mathrm{RN}$ apresenta aquele momento inicial com um pico de como grandes coisas vão acontecer, mas não apresentam tal patologia, não são evidenciados riscos para morte, temos um aparato razoável, estamos vendo a possibilidade melhora-la, estamos com planos através da Rede Cegonha, então às vezes é melhor ter a sua própria responsabilidade na decisão e avaliar o grau de necessidade de cuidado, contrário a isso também não me oponho a encaminhar (MÉDICO 8). 
TEMA 4: $O$ conhecimento sobre as políticas de saúde voltadas para o RN, em especial para o RN com BPN é deficiente, por vezes, teórico.

Apresenta o conhecimento sobre as políticas de saúde voltadas para o $\mathrm{RN}$. Durante as entrevistas nota-se que os participantes não detêm conhecimento sobre as políticas de saúde que promovem o cuidado especializado focado no $\mathrm{RN}$, pois as construções históricas dessas políticas surgiram há muitos anos, e até hoje muito se busca para torná-los efetivos e palpáveis.

Sinceramente, assim, eu sei o que a gente deve fazer, porque saúde é um direito de todos, mas, política me desculpe se tem, eu tô desatualizada, (risos), não ouvi falar (AUXILIAR DE ENFERMAGEM 4).

Assim, política que eu entendo é que o RN tem direito a assistência e isso não pode ser negado né, nem a mãe e nem ao RN, e isso é fornecido aqui (TÉCNICO DE ENFERMAGEM 10).

Tem uma construção histórica, se não me engano no período do sanitarismo já eram pensadas em políticas voltadas para mãe e $\mathrm{RN}$, explicitar por nome, eu não sei. Sei que o método canguru está aí no auge, acho que a Rede Cegonha também vai fortalecer essas políticas, assim acredito que estas são para RNs de forma geral e não com a especificidade do baixo peso, eu penso (ENFERMEIRO 10).

Ah, políticas, eu acho para assistência neonatal se não me engano acho que é sobre aleitamento, estamos engatinhando, mas vai dar certo porque o Governo não vai frustrar suas crianças (ENFERMEIRO 11).

Eu não estou muito por dentro das políticas, acho que elas ainda nem se efetivaram, mas com certeza o primeiro passo será com a
Rede Cegonha, se não for um sonho, será um triunfo (MÉDICO 9).

As políticas voltadas para o recém-nascido e a mãe, porque ambos fazem parte do processo, é o Método Canguru, que permite um foco de atenção à mãe e em especial a criança, os direitos garantidos pela ECA, pelo menos atendimento não pode ser recusado e promoção de aleitamento materno no Brasil, é mais ou menos assim ou tem outras?(...). (MÉDICO 10).

\section{DISCUSSÃO}

Detectou-se que a capacitação na área do cuidado ao RN, seja no parto ou puerpério não se apresenta com frequência, o tempo de duração de cursos e capacitações no período de 1semana, 2 meses até 6 meses, alguns com frequência mínima, participaram apenas de 2 ou 3 durante anos de profissão, mostrando assim a fragilidade da discussão em questão, revelando desinteresse em relação à educação permanente ou contínua com vistas ao foco no $\mathrm{RN}$; ou de maneira que ainda há profissionais que não estão preocupados com a qualificação dessa assistência, apenas 18 profissionais responderam ter vivenciado a capacitação, em muitos casos não ganham aplicabilidade aos RNs BPN condições favoráveis para eliminação de risco.

Assim, enfatizo que a educação permanente apresenta-se como um instrumento de grande importância no que diz respeito à aquisição de novos conhecimentos, principalmente porque melhora e facilita os processos de trabalho, beneficiando a sociedade com um bom atendimento e 
otimização dos cuidados prestados (TRONCHIN et al, 2005.)

Ao observar a fala dos profissionais ficou claro que o serviço não se apresenta realmente apto para prestar assistência ao $\mathrm{RN}$ com baixo peso, ao detectar nas falas “fazemos o que podemos”, é que às vezes embora apresentem muito tempo no serviço, e tenham vivenciado e presenciado momentos inexplicáveis, e se deparado com inúmeras situações, por vezes demonstram acomodação ou indignados porque o serviço também não detém suporte necessário, então seguem a rotina de primeiros cuidados ao $\mathrm{RN}$ prestados pela enfermagem e ao se deparar com algo mais grave, a única ação é convocar o médico.

Uma das medidas primordiais para $\mathrm{RN}$ de baixo peso é a prática do incentivo ao aleitamento materno, pois através do leite materno o $\mathrm{RN}$ consegue ganhar peso $\mathrm{e}$ manter-se protegido de agravos que pode por em risco sua sobrevivência. Nas entrevistas, apenas dois profissionais mencionaram o incentivo ao aleitamento materno. Como colocado pela Auxiliar de Enfermagem 1 que mencionou "além de tudo ofereço leite materno em seringa", quando o certo deveria se oferecer o leite em copinho ou colherzinha, ou dependendo do baixo peso do $\mathrm{RN}$ por sonda oro-gástrica.

A rede hospitalar deveria dispor de maiores recursos para o cuidado com o $\mathrm{RN}$, como a UTIN para tratar e receber RN em estado de saúde critico. Além disso, é necessária a implantação de um banco de leite, haja vista que crianças com baixo peso apresentam dificuldades para amamentar, e outras já nascem com sofrimento respiratório, dentre outras situações que são capazes de comprometer o quadro de saúde, que pode de rapidamente evoluir para um óbito (BRASIL, 2009).

$\mathrm{Na}$ fala do Médico 5, há o relato de que "aqui eu não costumo agir por impulso, mas se não há UTI neonatal, vou buscar reforços”. Ele apresentou algo característico em intercorrências, que é o seu comportamento mediante a situação, mas além de buscar reforços, não apenas o profissional médico, mas todos os outros membros da equipe devem ser capazes de identificar aspectos no RN que revelem condições de risco, como períodos de apnéia, hipotermia, hipoglicemia, infecções, hipocalcemia, dentre outras. Além de detectálos é necessário conhecer que cuidados específicos devem ser direcionados aos mesmos.

Na fala do Médico 6 tem-se que "as medidas tomadas ocorrem depois de avaliarmos as condições do $R N$, existem problemas que podem ser detectados ao nascimento que tem como precursor o baixo peso, então a investigação torna-se fundamental" ao detectar o baixo peso algumas medidas devem ser tomadas algumas 
semelhantes a de um RN a termo e outras bastantes significativas e específicas para o RN BPN que é assegurar proteção térmica, prevenir e tratar hipoglicemia e assegurar adequada cota calórica, observar a resposta de sucção, bem como realizar os procedimentos imediatos e mediatos (BRASIL, 2009).

Ao avaliar algumas falas foi perceptível que alguns profissionais não querem arriscar "Às vezes sai melhor não arriscarmos encaminhá-lo", arriscar? Um fator que deve ser observado nos serviços de saúde é a questão do risco/benefício, alguns profissionais são capazes de expor e reconhecer que o seu ambiente de trabalho não tem suporte para realização de alguns procedimentos em casos de urgência, mas muitos não compreendem o que é a referência, o suporte que a mesma apresenta, sabe-se que o risco de transferência ocorre durante o percurso, pois determinadas situações em RN podem constituir risco.

$\mathrm{Na}$ fala "quando ocorre uma intercorrência geralmente eles ligam pra Mossoró”, eles quem? A quem é atribuída à função da referência? Nas falas dos enfermeiros evidenciou-se que a maioria dos casos fica em sua responsabilidade, e que os profissionais médicos seriam os mais favoráveis de maneira que a partir do diagnóstico estes podem buscar contatos e vínculos que já tem em outra instituição e apresentar o quadro do RN, essa responsabilidade deve ser atribuída de forma específica e palpável a esses dois profissionais de maneira que não sobrecarregue apenas ao enfermeiro, haja vista que este ainda tem outras atribuições no setor.

Os profissionais entrevistados desconhecem ao certo quais políticas são voltadas para o $\mathrm{RN}$, alguns trazem o conhecimento acerca do método canguru, mas desconhecem toda a construção histórica que antecedeu ao mesmo, "Sei que o método canguru está aí no auge” mas não consegue discutir acerca dos objetivos do mesmo, desconhecem todo o arcabouço teórico de planejamento e funções que o método canguru dispõe, alguns confundem sobre o que diz respeito a Rede Cegonha e outros até acreditam que a mesma não terá suporte para garantir atenção a gestante e ao seu filho, de maneira que só reforçam que a assistência neonatal vem engatinhando (BRASIL, 2011).

\section{CONSIDERAÇÕES FINAIS}

Ficou evidenciada a fragilidade dos serviços de saúde em relação à assistência à saúde ao RN com baixo peso. Embora em alguns momentos dos depoimentos dos profissionais de saúde fossem perceptíveis à preocupação com o cuidado prestado ao $\mathrm{RN}$, eles demonstram que é necessário que a educação permanente seja realizada, melhorar o quadro profissional na área de neonatologia 
e a disponibilidade de aparatos tecnológicos

para esses estabelecimentos de saúde.

Foi observado o alto índice de parto cesáreo nesta realidade, evidenciando que o mesmo pode ser considerado fator crucial para risco de RN com baixo peso ao nascer e que, além disso, quebra com a preparação fisiológica do parto dificultando o aleitamento materno e favorecendo complicações neonatais após o nascimento.

O cuidado ao RN com Baixo Peso ao Nascer não difere do cuidado a outros $\mathrm{RN}$, o suporte dado em Situação de Intercorrência segue as regras da Referência e Contra Referência para Unidades Mais Complexas e o conhecimento sobre as políticas de saúde voltadas para o $\mathrm{RN}$, em especial para o $\mathrm{RN}$ com BPN é deficiente.

Urge a necessidade de melhorias em relação aos serviços de saúde é necessário pensar na atenção à saúde da mãe e do recémnascido, elaborando estratégias como novos cursos de atualização, as instituições devem configurar-se com vistas à ampliação estrutural, aparato tecnológico, equipe multiprofissional especializada no serviço neonatal, criação de banco de leite, fortalecimento do vínculo para manter a referência e contra referência, e conhecimento sobre as políticas de saúde voltadas para o recém-nascido.

\section{REFERÊNCIAS}

BRASIL, Ministério da Saúde. Secretaria de Atenção à Saúde. Departamento de Ações Programáticas e Estratégicas. Atenção à saúde do recém-nascido: guia para os profissionais de saúde / Ministério da Saúde, Secretaria de Atenção à Saúde, Departamento de Ações Programáticas e Estratégicas. Brasília: Ministério da Saúde, 2011.

BRASIL, Ministério da Saúde. Iniciativa Hospital Amigo da Criança : revista, atualizada e ampliada para o cuidado integrado : módulo 3 : Promovendo e incentivando a amamentação em um Hospital Amigo da Criança : curso de 20 horas para equipes de maternidade / Fundo das Nações Unidas para a Infância, Organização Mundial da Saúde. - Brasília : Editora do Ministério da Saúde, 2009.

CARNIEL, E. de F.; ZANOLLI, M. de L.; ANTONIO, M. A. R. de G. M. e MORCILLO, A. M. Determinantes do baixo peso ao nascer a partir das Declarações de Nascidos Vivos. Rev. bras. epidemiol. [online]. 2008, vol.11, n.1, pp. 169-179.

IBGE. Censo Demográfico 2010. Disponível em:

〈http://www.ibge.gov.br/cidadesat/topwindo w.htm?1>. Acesso em: 15 de Maio de 2013.

KENNER, C. Enfermagem Neonatal. Rio de Janeiro: Reichmann \& Affonso, 2001.

KRAMER, M.S. Determinants of low birth weight: methodological assessment and metaanalysis. Bull World Health Organ, 1987; 65(5): 663-737.

PAULA, C. G de et al. Baixo peso ao nascer: fatores socioeconômicos, assistência pré-natal e nutricional - uma revisão. Revista Augustus, Rio de Janeiro, Vol. 14, N. 29, Fevereiro de 2010, Semestral. 
TRONCHIN, D. M. R. et al. Gerenciamento em enfermagem. Rio de Janeiro (RJ): Guanabara Koogan, 2005.

ZAMBONATO, A. M. K. et al. Fatores de risco para nascimento de crianças pequenas para idade gestacional. Rev. Saúde Pública, São Paulo, v. 38, n. 1, Fev. 2004. 